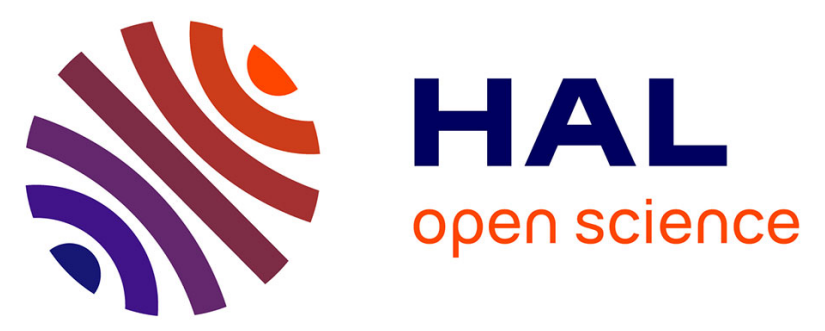

\title{
Two octave supercontinuum generation by cascaded intermodal four-wave mixing in a step index few-mode fibre
}

Solveig Perret, Gil Fanjoux, Lionel Bigot, Julien Fatome, Guy Millot, John Michaël Dudley, Thibaut Sylvestre

\section{To cite this version:}

Solveig Perret, Gil Fanjoux, Lionel Bigot, Julien Fatome, Guy Millot, et al.. Two octave supercontinuum generation by cascaded intermodal four-wave mixing in a step index few-mode fibre. Nonlinear Photonics, Jul 2018, Zurich, Switzerland. 10.1364/NP.2018.NpTh2I.1 . hal-02300646

\section{HAL Id: hal-02300646 https://hal.science/hal-02300646}

Submitted on 7 May 2021

HAL is a multi-disciplinary open access archive for the deposit and dissemination of scientific research documents, whether they are published or not. The documents may come from teaching and research institutions in France or abroad, or from public or private research centers.
L'archive ouverte pluridisciplinaire HAL, est destinée au dépôt et à la diffusion de documents scientifiques de niveau recherche, publiés ou non, émanant des établissements d'enseignement et de recherche français ou étrangers, des laboratoires publics ou privés. 


\title{
Two octave supercontinuum generation by cascaded intermodal four-wave mixing in a step-index few-mode fiber
}

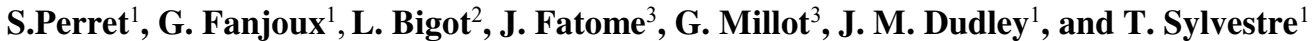 \\ ${ }^{I}$ Institut FEMTO-ST, CNRS, Université Bourgogne Franche-Comté, 25000 Besançon, France \\ ${ }^{2}$ PhLAM Laboratoire de Physique des Lasers Atomes et Molécules, CNRS, Université de Lille, 59655 Villeneuve-d'Ascq, France \\ ${ }^{3}$ Laboratoire Interdisciplinaire Carnot de Bourgogne, CNRS, Université Bourgogne Franche-Comté, 21000 Dijon, France \\ Author e-mail address: solveig.perret@femto-st.fr
}

\begin{abstract}
We demonstrate broadband supercontinuum generation from $560 \mathrm{~nm}$ to $2350 \mathrm{~nm}$ in a simple step-index few-mode fiber pumped with a microchip laser at $1064 \mathrm{~nm}$ through cascaded intermodal four-wave mixing and Raman scattering.

OCIS codes: (060.4370) Nonlinear optics; (060.2310) Fiber optics
\end{abstract}

The study of intermodal nonlinear interactions in multimode fibers (MMFs) has recently seen greatly renewed interest because of a number of major experimental demonstrations in emerging key areas of laser physics and fiber optics [1]. Specifically, MMFs have been shown to possess specific modal properties that mediate a number of spatiotemporal nonlinear effects that are fundamentally different from those seen in standard single-mode fibers. These include the observation of multimode solitons [2], cascaded intermodal four-wave mixing (FWM) $[3,4]$, geometric parametric instabilities [5], spatial beam self-cleaning [6], and multimode supercontinuum (SC) generation $[7,8]$.

To date, most recent observations have been performed using graded-index MMFs featuring weak intermodal dispersion, although intermodal nonlinear mixing has also been reported in step-index fibers with Bessel beams [9]. In this work, we extend the study of novel nonlinear effects to step-index few mode fibers to show that they can be conveniently applied to far-detuned (visible and mid-infrared) cascaded intermodal FWM and supercontinuum generation. We demonstrate in particular SC generation from $560-2350 \mathrm{~nm}$ by coupling a Q-switched picosecond microchip laser at $1064 \mathrm{~nm}$ into a 50-m long and $15 \mu \mathrm{m}$-core step-index germanium-doped silica fiber. Figure 1(a) shows the experimental setup and the main LP modes supported by the fiber at $1064 \mathrm{~nm}$. The output SC light was measured using three different optical spectrometers to cover the full wavelength range, and the modal distribution of all generated FWM sidebands was imaged using a CCD camera and a diffraction grating. Figure 1(b) shows the output supercontinuum spectrum generated at a maximum coupling efficiency (average output power of $13 \mathrm{~mW}$ ). The inset shows the far-field optical mode in the visible. Note that for this fiber, the zero dispersion wavelength is $1300 \mathrm{~nm}$, and so the pump wavelength is in the normal dispersion regime of the fiber. SC generation in this case arises from cascaded stimulated Raman scattering for the broadening in the infrared, and far-detuned intermodal FWM for extension towards the visible.
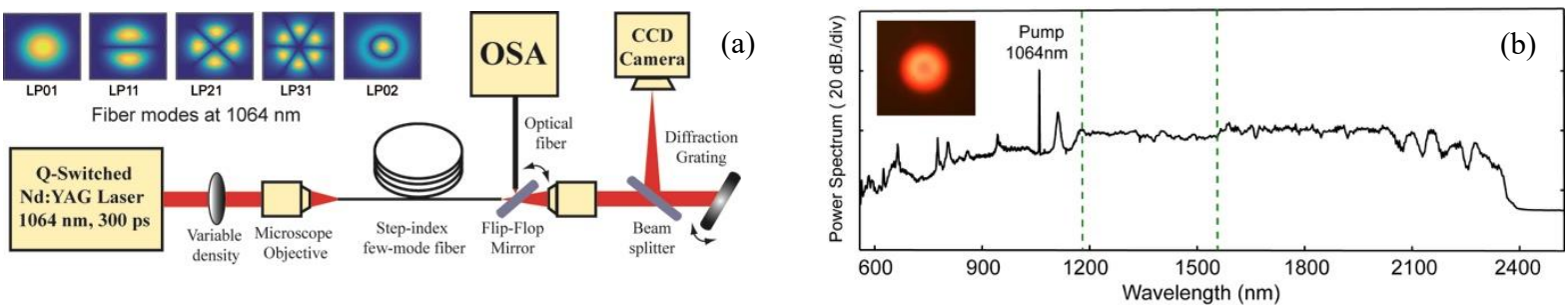

Fig. 1. (a) Experimental setup and (b) supercontinuum spectrum generated in a few-mode step-index fiber from $560 \mathrm{~nm}$ to $2350 \mathrm{~nm}$, measured with 3 different optical spectrometers to cover all the wavelength range (the dashed lines indicate the 3 measurement ranges used). The average output power is $13 \mathrm{~mW}$.

To obtain further insight into the underlying physical mechanisms, additional experiments were performed for a shorter fiber length of $5 \mathrm{~m}$ and for a range of pump powers. For this case, Fig. 2(a) shows the measured output spectra over the range 560-1200 nm as a function of pump power with the corresponding output far-field images of the generated modal sidebands. As well as the residual pump at $1064 \mathrm{~nm}$ (and microchip CW pump at $800 \mathrm{~nm}$ ), we see the generation of a first-order Raman Stokes line at $1110 \mathrm{~nm}$ and two narrow parametric sidebands at $968 \mathrm{~nm}$ 
and $1174 \mathrm{~nm}$, respectively. Those sidebands are generated in the $\mathrm{LP}_{01}$ and $\mathrm{LP}_{11}$ modes by intermodal FWM involving two photons in a mixed LP pump mode (see Fig. 2(b)). Interestingly, those two parametric sidebands are strongly enhanced by the Raman gain as the Stokes sideband falls in the gain region for secondorder Stokes Raman scattering. At higher power, intermodal FWM involving the pump at $1064 \mathrm{~nm}$ generates a signal at $948 \mathrm{~nm}$ and an idler at $1210 \mathrm{~nm}$ (not visible on Fig. 2(a)). The two signals at 948 and $968 \mathrm{~nm}$ are strong enough to generate two other parametric sidebands at $779 \mathrm{~nm}\left(\mathrm{LP}_{01}\right)$ and at $667 \mathrm{~nm}\left(\mathrm{LP}_{02}\right)$, respectively, by cascaded intermodal FWM. To confirm these experimental results, we numerically calculated (using COMSOL) the different phase-matching conditions using the effective indices and the dispersion coefficients of all interacting modes using a step-index fiber model. Good agreement was found between predicted and measured wavelengths of parametric sidebands.
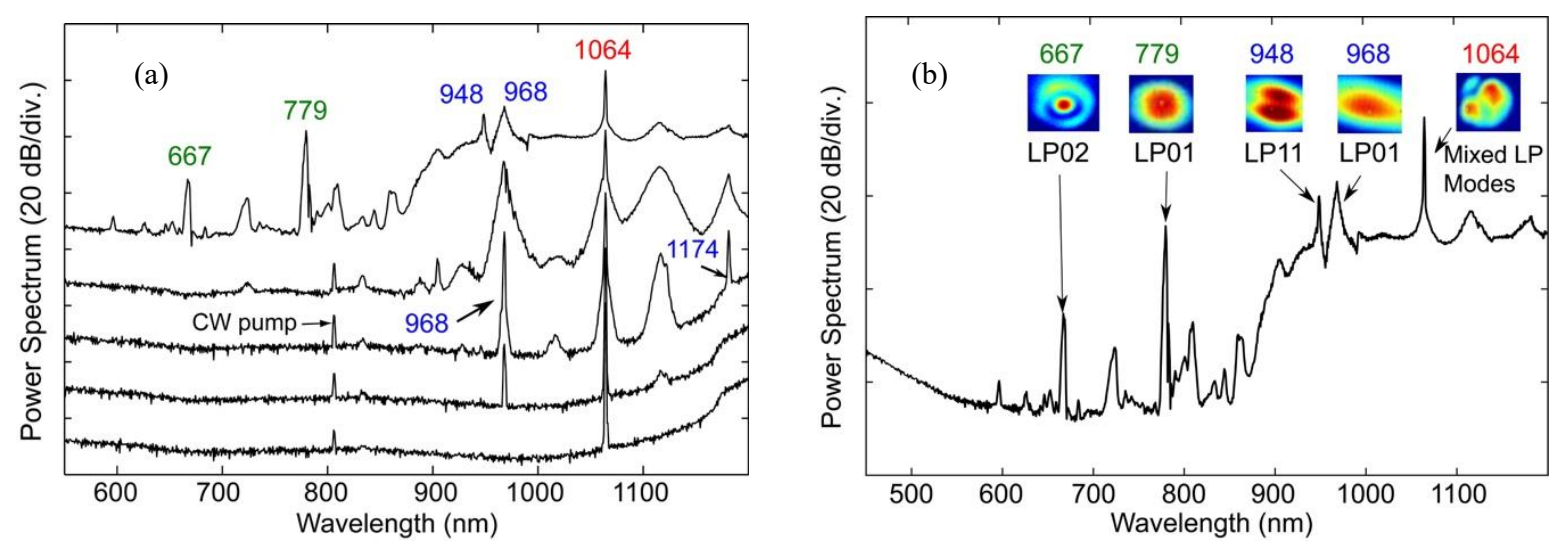

Fig. 2. (a) Experimental output spectra for different output pump power of (from bottom to top) $0.85 \mathrm{~mW}, 1.6 \mathrm{~mW}, 2.6 \mathrm{~mW}, 3.5 \mathrm{~mW}$ and 8.1 $\mathrm{mW}$ at a fiber length of $5 \mathrm{~m}$; (b) fiber output spectrum for the maximum mean power on which the FWM-wavelength and their associated LP modes are imaged with a CCD camera after passing through a diffraction grating.

These results are significant in showing that wideband fiber-based SC generation spanning two octaves from 560-2350 $\mathrm{nm}$ can be achieved in simple step-index few-mode fiber pumped in the normal dispersion regime with a Q-switched microchip laser at $1064 \mathrm{~nm}$. We have identified the spectral broadening as arising from cascaded Raman scattering and intermodal nonlinear four wave mixing. We anticipate that the results demonstrated in this work may provide a convenient and novel approach enabling efficient SC generation far from the zero-dispersion wavelength of optical fibers, and may stimulate new possibilities for technological applications of multimode and few-mode fibers.

\section{References}

[1] L. G. Wright, D. N. Christodoulides, F. W. Wise, "Controllable spatiotemporal nonlinear effects in multimode fibres," Nat. Photon. 9, 306 (2015).

[2] Z. Zhu, L. G. Wright, D. N. Christodoulides and F. W. Wise, "Observation of multimode solitons in few-mode fiber" Opt. Lett. 20 , 4819 (2016).

[3] J. Demas, G. Prabhakar, T. He, and S. Ramanchandran, "Broadband and wideband parametric gain via intermodal four-wave mixing in optical fiber", in "Conference on Laser and Electro-Optics," (Optical Society of America, 2017), p. SM3M.1.

[4] R. Dupiol, A. Bendahmane, K. Krupa, A. Tonello, M. Fabert, B. Kibler, T. Sylvestre, A. Barthelemy, V. Couderc, S. Wabnitz, and G. Millot, "Far-detuned cascaded intermodal four-wave mixing in a multimode fiber," Opt. Lett. 42, 1293-1296 (2017).

[5] K. Krupa, A. Tonello, A. Barthelemy, V. Couderc, B. M. Shalaby, A. Bendahmane, G. Millot, and S. Wabnitz, "Observation of Geometric Parametric Instability Induced by the Periodic Spatial Self-Imaging of Multimode Waves.” Phys. Rev. Lett. 18, 183901 (2016).

[6] K. Krupa, A. Tonello, B. M. Shalaby, M. Fabert, A. Barthelemy, G. Millot, S. Wabnitz, and V. Couderc, "Spatial beam self-cleaning in multimode fibres," Nat. Photon. 4, 237 (2017).

[7] M. A. Eftekhar, L. G. Wright, M. S. Mills, M. Kolesik, R. A. Correa, F. W. Wise and D. N. Christodoulides, "Versatile supercontinuum generation in parabolic multimode optical fibers," Opt. Exp. 8, 9078 (2017).

[8] K. Krupa, C. Louot, V. Couderc, M. Fabert, R. Guenard, B. M. Shalaby, A. Tonello, D. Pagnoux, P. Leproux, A. Bendahmane, R. Dupiol, G. Millot, S. Wabnitz, "Spatiotemporal characterization of supercontinuum extending from the visible to the mid-infrared in a multimode gradedindex optical fiber," Opt. Lett. 41, 5785 (2016).

[9] J. Demas, P. Steinvurzel, B. Tai, L. Rishoj, Y. Chen and S. Ramanchandran, "Intermodal nonlinear mixing with Bessel beams in optical fiber," Optica 2, 1 (2015). 